\title{
¿Por qué se aprobó el voto voluntario en Chile? Razones y argumentos que impulsaron la reforma
}

\author{
Why was the voluntary vote passed in Chile? \\ Reasons and arguments that drove reform
}

\author{
MAURICIO MORALES QUIROGA ${ }^{1}$ \\ Universidad de Talca, Chile \\ GONZALO CONTRERAS ${ }^{2}$ \\ Universidad Diego Portales, Chile
}

RECEPCIÓN: 23/05/2017 • ACEPTACIÓN: 02/10/2017

RESUMEN: Teóricamente, con voto voluntario baja la participación electoral y tienden a votar más los ricos que los pobres, generando lo que la literatura denomina como sesgo de clase. Entonces, ¿qué lleva a los políticos a optar por un régimen de voto voluntario? Considerando el caso de Chile, nuestro objetivo es identificar las razones que impulsaron la reforma. Metodológicamente, utilizamos tres fuentes de información: discusión legislativa, encuestas de opinión y una inédita encuesta aplicada al 100\% de los diputados luego de aprobada la reforma. Nuestros resultados indican que la reforma se aprobó producto de la interacción entre intereses estratégicos de la coalición de gobierno (de centro-izquierda) y de la oposición. Mientras el gobierno impulsó la reforma creyendo que los nuevos votantes serían

1. Académico Jornada Completa de la Universidad de Talca, Chile. Director del Centro de Análisis Político de la Universidad de Talca. Investigador adjunto del Centro de Estudios de Conflicto y Cohesión Social (CONICYT/FONDAP/15130009). Sus trabajos han sido publicados en Journal of Ethnic and Migration Studies, Democratization, Latin American Politics\&Society, Latin American Research Review, Revista de Ciencia Política, Estudios Políticos, Política y Gobierno, entre otras. email: mmoralesq@utalca.cl. Este artículo recibió financiamiento del Proyecto FONDECYT número 1170944.

2. Cientista Político Universidad Diego Portales (UDP). email: gonzalocontreras.ag@gmail.com. 
principalmente de centro-izquierda, la derecha lo hizo pensando en que sus nuevos electores tendrían mayor probabilidad de votar dado su mayor nivel de ingresos. A esto se sumó un amplio apoyo ciudadano a la reforma expresado en las encuestas, lo que pudo presionar a los diputados. Constatamos que en la centro-izquierda hubo rápidas señales de arrepentimiento, pues el 70\% de los diputados -en una encuesta hecha a meses de la reforma- se mostró partidario del voto obligatorio.

PALABRAS CLAVE: Voto voluntario - participación - Chile - encuestas - diputados

ABSTRACT: Theoretically, a voluntary vote results in low voter turnout and a stronger tendency to vote among the rich than the poor, generating what the literature calls class bias. So what leads politicians to opt for a voluntary voting regime? The object of this article is to identify the reasons that led to the reform in Chile. In methodological terms, we used three sources of information: legislative discussion, opinion polls and an unpublished survey applied to $100 \%$ of deputies some months after the reform was passed. Our results indicate that the reform was passed as a result of interaction between the strategic interests of the (center-left) government coalition and the opposition. While the coalition pushed for reform thinking that new voters would be primarily center-left, the right wing supported the proposal in the belief that their new voters would be more likely to vote given their higher income. To this was added broad citizen support for the reform expressed in opinion polls, which may have pressured the deputies. We found that in the center-left there were quick signs of repentance, since in a survey carried out some months after the reform $70 \%$ of the deputies were in favor of compulsory voting.

KEYWORDS: Voluntary vote - voter turnout -Chile - polls - deputies

\section{Introducción}

Existe una amplia literatura sobre los orígenes de los sistemas electorales tanto en América Latina ${ }^{3}$ como en el mundo ${ }^{4}$. A la par, hay un grupo de autores que se pregunta por el origen y los efectos de los regímenes electorales y, en particular, del

3. Wills-Otero, 2009.

4. Boix, 1999; Benoit, 2007; Colomer, 2007. 
impacto del voto obligatorio y voluntario sobre la participación electoral. Para casi todos, la institución del voto obligatorio es un poderoso predictor del volumen de participación ${ }^{5}$. Para otros, si bien esta institución es importante, también lo es la composición socioeconómica de los votantes ${ }^{6}$, el tamaño de la población ${ }^{7}$, el porcentaje de población indígena ${ }^{8}$, la competencia electoral ${ }^{9}$, la sucesión de elecciones ${ }^{10}$ y la existencia de partidos de izquierda con alta capacidad de convocatoria ${ }^{11}$.

La mayoría de estos trabajos está más pendiente de los efectos de cada régimen electoral, que de las motivaciones de los políticos para transitar desde el voto obligatorio al voto voluntario o viceversa. Metodológicamente, entonces, ocupan al régimen electoral como una variable independiente de la participación, pero no como una variable dependiente de los intereses e incentivos de los partidos. Existe abundante literatura que recomienda el voto obligatorio y que puntualiza dos peligros del voto voluntario ${ }^{12}$ : la caída de la participación y la agudización del sesgo de clase.

Por lo anterior, no deja de sorprender que un país como Chile -reconocido como un sistema de partidos altamente institucionalizado- haya adoptado el régimen de voto voluntario. La participación se había reducido sistemáticamente desde 1989 cuando se utilizaba un régimen de una particular combinación: inscripción voluntaria en los registros electorales y voto obligatorio. En este régimen también existía el sesgo de clase. Por tanto, resulta llamativo que los políticos hayan optado por un régimen de voto voluntario donde, teóricamente, no solo bajaría la participación, sino que también se profundizaría ese sesgo de clase. Si bien con la inscripción automática el padrón aumentó de 8 a más de 13 millones de electores, nada garantizaba un incremento de la participación.

Nuestro argumento es que la aprobación de la inscripción automática en los registros electorales y del voto voluntario en Chile obedeció a la coincidencia entre los intereses estratégicos de los partidos de gobierno y de oposición. Los intereses estratégicos de los partidos de gobierno se basaban en la creencia de que los nuevos

5. JaCKMAN, 1987; Blais, 2008.

6. Lijphart, 1997; Gallego, 2010.

7. Geys, 2006; Bernhagen y Marsh, 2007.

8. LeHoucQ Y Wall, 2004.

9. INDRIDASON, 2008.

10. Rallings y Borisyuk, 2003.

11. MaCKERRAS y MCAllister, 1999.

12. LiJPHART, 1997; MACKerRas y McAllister, 1999; JACKMAN, 1987; GeYs, 2006; Blais, 2008; Gallego, 2010. 
votantes -predominantemente jóvenes- eran mayoritariamente de centro-izquierda. Por tanto, al incluirlos directamente en el padrón por medio de la inscripción automática- evitando así que hicieran el trámite burocrático de inscripción ante la junta electoral- obtendrían beneficios electorales. Los intereses estratégicos de los partidos de derecha, en tanto, obedecían a que si bien la mayoría de los nuevos electores eran de centro-izquierda, existía más predisposición a votar en los nuevos electores de derecha. Por último, estaba la sensación de que con voto voluntario el poder del dinero sería más decisivo en la movilización electoral. Como los partidos de derecha contaban (y cuentan) con más recursos, entonces el voto voluntario les abría mayores posibilidades de éxito electoral. El escenario favorable a la reforma se complementaba con un amplio respaldo ciudadano al voto voluntario expresado en las encuestas de opinión. En definitiva, este cambio institucional contó con dos condiciones básicas: consenso político y apoyo popular.

Subrayamos que, metodológicamente, este trabajo se basa en revisión de la discusión legislativa, entrevistas a personeros claves, encuestas de opinión, y una encuesta aplicada a los 120 diputados que votaron la reforma a la ley orgánicoconstitucional discutida en 2011 y promulgada a inicio de 2012.

El artículo se divide en seis breves secciones. Primero, presentamos el argumento central. Segundo, mostramos la evolución de la participación en Chile. Tercero, evaluamos el estado de la literatura chilena sobre la discusión entre voto obligatorio y voluntario. Cuarto, desarrollamos la historia de la ley junto con un análisis de las opiniones de los diputados. Quinto, explicamos las posibles causas de por qué se aprobó la reforma. Sexto, evaluamos los efectos esperados del voto voluntario para gobierno y oposición.

\section{El argumento}

Tanto en Chile como en América Latina se dio un proceso acumulativo de reformas al régimen electoral durante el $\mathrm{XX}^{13}$. La tendencia regional apuntó hacia la expansión del sufragio universal, generando así la incorporación de sectores medios emergentes y de campesinos ${ }^{14}$. Chile no fue la excepción. Desde fines del siglo XIX se dio un lento proceso de apertura caracterizado por la generación de instituciones destinadas

13. Collier y Collier, 1991.

14. LEVITSKY y ROBERTS, 2011. 
a transparentar las elecciones ${ }^{15}$. En el siglo XX, en tanto, y en particular en la segunda parte, se instituyeron nuevos mecanismos de incorporación que incluyeron a mujeres y analfabetos. La expansión del padrón fue impulsada por partidos de derecha y de izquierda. Los partidos de derecha apoyaron el voto femenino porque tenían la certeza de que las mujeres preferían partidos conservadores ${ }^{16}$. Los partidos de izquierda, en tanto, hicieron lo propio con los analfabetos bajo el supuesto de que sus preferencias electorales estaban orientadas hacia su sector político ${ }^{17}$. A esto se sumó el establecimiento de la cédula única como mecanismo de transparencia electoral en 1952, y en 1962 el aumento de las sanciones para quienes no votaban ${ }^{18}$. Esta última reforma contribuyó a que la participación electoral prácticamente se duplicara comparando las presidenciales de 1958 y $1964^{19}$.

El régimen de Pinochet (1973-1990) mantuvo el carácter obligatorio del voto, pero con inscripción voluntaria en los registros electorales. Todas las personas de 18 años y más estaban habilitadas para inscribirse en los registros. Una vez inscritos, votar era obligatorio. Junto con la reinauguración de la democracia, la participación fue sustancialmente alta, pero fue decreciendo desde fines de los 90. La población habilitada para votar subía año a año, pero la porción de inscritos se estancó. Esta baja participación llevó a varias propuestas en torno al carácter del voto. Es decir, si mantenerlo como obligatorio o cambiarlo a voluntario. Finalmente, se optó por esta última alternativa.

Este nuevo régimen debutó para las elecciones municipales de 2012. La participación, que bordeó el $60 \%$ en las elecciones municipales de 2008, bajó al $41 \%$ en las elecciones locales de 2012. En consecuencia, y al igual como muestra la experiencia comparada, el voto voluntario produjo caídas significativas en la participación electoral. Igual cosa sucedió en las elecciones presidenciales de 2013, donde la participación se desplomó del 59\% al 49\% respecto a 2009.

En este artículo, como hemos dicho, nos preguntamos por las razones que motivaron el cambio del voto obligatorio al voto voluntario, una iniciativa generada en el gobierno de Ricardo Lagos (2000-2006) y aprobada en el de Michelle Bachelet (2006-2010). En síntesis, sugerimos lo siguiente:

15. GамвоА, 2011.

16. MAZA, 1995.

17. Cruz-Coke, 1985; Navia, 2004.

18. Valenzuela, 2003.

19. NAVIA, 2004: 87. 
a) En el debate sobre la reforma constitucional de 2009 que consagraba el voto voluntario, se apeló a argumentos normativos asociados a entender el voto como un derecho y no como un deber. Comprensiblemente, se escondieron los argumentos empíricos a fin de no contaminar la discusión con los intereses estratégicos de las coaliciones. Sostenemos que, en realidad, la reforma se aprobó dada la intersección de los intereses estratégicos de las dos coaliciones más importantes: la Concertación (centro-izquierda) y la Alianza (derecha). Basados en encuestas de opinión, existían argumentos para pensar que los nuevos votantes terminarían por respaldar mayoritariamente a alguna de las coaliciones. En la Concertación estaba la idea de que el volumen de nuevos votantes de centro-izquierda era mucho mayor respecto a los de derecha. En la Alianza, si bien se reconocía esta evidencia, se subrayaba que la predisposición a votar era mayor en los votantes de derecha.

b) También en esta fase de discusión constitucional, se apeló al amplio apoyo ciudadano que tenía la reforma. Encuestas de 2010 y 2011 mostraban que la preferencia por el voto voluntario bordeaba los tres cuartos de la población.

c) La segunda fase de discusión se desarrolló en el gobierno de Sebastián Piñera (2010-2014). Luego de aprobada la reforma constitucional, correspondía discutir la ley orgánica que pondría en marcha el voto voluntario. Acá aparecieron argumentos empíricos contrarios a la reforma, pero que -nuevamente- no hacían alusión al interés estratégico de los partidos, sino que a los efectos del voto voluntario sobre el volumen de participación y la eventual profundización del sesgo de clase. Es decir, que participaran más las personas de estrato alto en desmedro de los pobres ${ }^{20}$.

d) Adicionalmente, se comenzó a discutir sobre el posible efecto del dinero en la política bajo la nueva regla, argumentándose que con voto voluntario aumentaría el gasto en campaña. Esto, porque los partidos tendrían doble trabajo: convencer a los electores y asegurarse de que fueran a votar. Sin embargo, ninguno de estos argumentos sirvió para, al menos, incluir incentivos a la participación. No fueron pocos los diputados de la Concertación que -en entrevistas de carácter privado- reconocieron haber aprobado la nueva ley orgánica sin estar de acuerdo. Esto, por lo costoso que resultaba aparecer votando en contra de lo que había sugerido el gobierno "súper-popular" 
de Bachelet, y por el amplio apoyo que gozaba la reforma en la opinión pública. En una encuesta aplicada por el Observatorio Político-Electoral a los 120 diputados que componían la Cámara en 2010, solo el 26\% de los representantes de la Concertación estaba de acuerdo con que el voto fuese voluntario. El 74\% restante apoyaba el voto obligatorio. En la Alianza, en tanto, el apoyo al voto voluntario superaba los dos tercios.

\section{Participación electoral en Chile: el contexto de la reforma}

Con la aplicación del voto voluntario, la participación electoral en Chile decreció de $58 \%$ en las municipales de 2008 a 41\% en las municipales de 2012. En la elección presidencial de 2013 se repitió idéntico patrón: la participación cayó en más de 10 puntos. La participación venía decreciendo a un ritmo acelerado, pero con el voto voluntario esa caída fue más violenta.Tomando en cuenta las elecciones presidenciales, en 1989 votó casi el 89\% de la población en edad de votar (PEV), mientras que en 2009 (segunda vuelta), lo hizo tan solo el 59,6\%, para caer al 49,3\% en la primera vuelta presidencial de 2013, y a $42 \%$ en la segunda vuelta. En consecuencia, si bien Chile se ha destacado por su proceso de consolidación democrática, esto convive con un bajo interés en la política por parte de la ciudadanía y que se expresa en una caída significativa en los niveles de participación ${ }^{21}$.

A nivel municipal, el porcentaje de abstención también ha aumentado sustancialmente. Calculamos la abstención de acuerdo al porcentaje que representan los votos emitidos en función del total de la población en edad de votar. En el antiguo régimen electoral (de inscripción voluntaria y voto obligatorio) la abstención se calculaba en función solo del total de inscritos, por lo que su valor estaba subestimado. Así, por ejemplo, la abstención en 1992 alcanzó el 10\% de acuerdo a este cálculo. Sin embargo, y considerando como universo a toda la población en edad de votar, para 1992 la abstención fue del 20,6\%. Para 2012, en tanto, y con voto voluntario, subió al 59\% (Ver gráfico 1).

Otra cuestión relevante está en la composición de esa participación. Previo a la reforma, el padrón de votantes se fue envejeciendo elección tras elección. Las tasas de inscripción en los segmentos jóvenes decrecieron de manera sustantiva. Si en 1989 más de un tercio de los votantes tenía entre 18 y 29 años, en 2009 esa cifra descendió al 8,8\%. Mientras tanto, los adultos de 60 años y más crecieron

21. Morales, 2010, 2011, 2012 y 2012a; Navia, 2004; Luna y Altman, 2011. 
del $14,5 \%$ en 1988 al 25,7\% en 2009. Con la entrada en vigencia de la inscripción automática y el voto voluntario, la porción de jóvenes sobrepasó el $25 \%$ de la población habilitada para votar. El gráfico 2 muestra comparativamente la composición por edad del antiguo y del nuevo padrón.

\section{Gráfico 1.}

\section{Abstención y votación válida en las elecciones municipales 1992-2012}

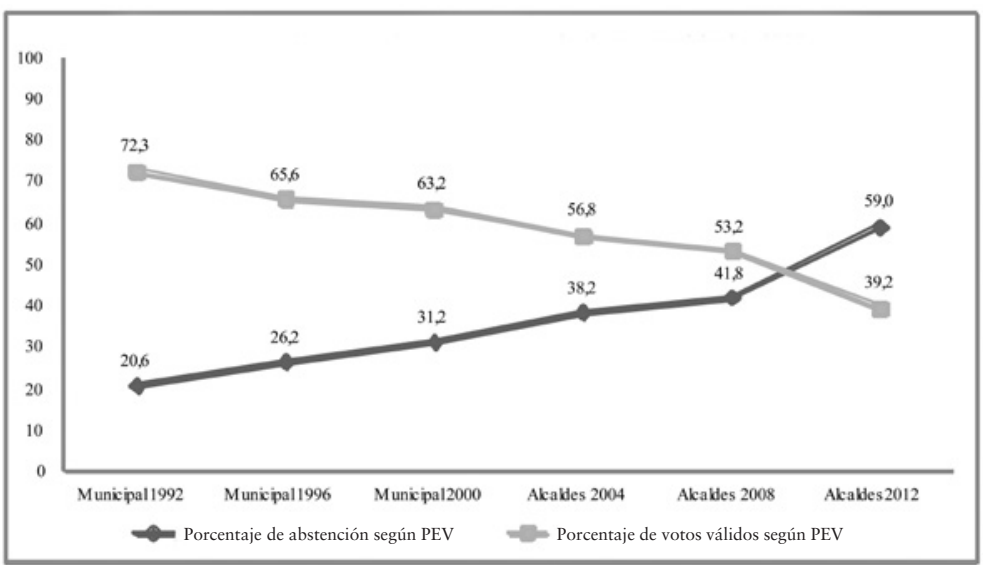

Fuente: Elaboración propia con datos de www.ine.cl, www.servel.cl, www.elecciones.gov.cl

\section{Gráfico 2.}

Composición etárea del padrón pre y post reforma

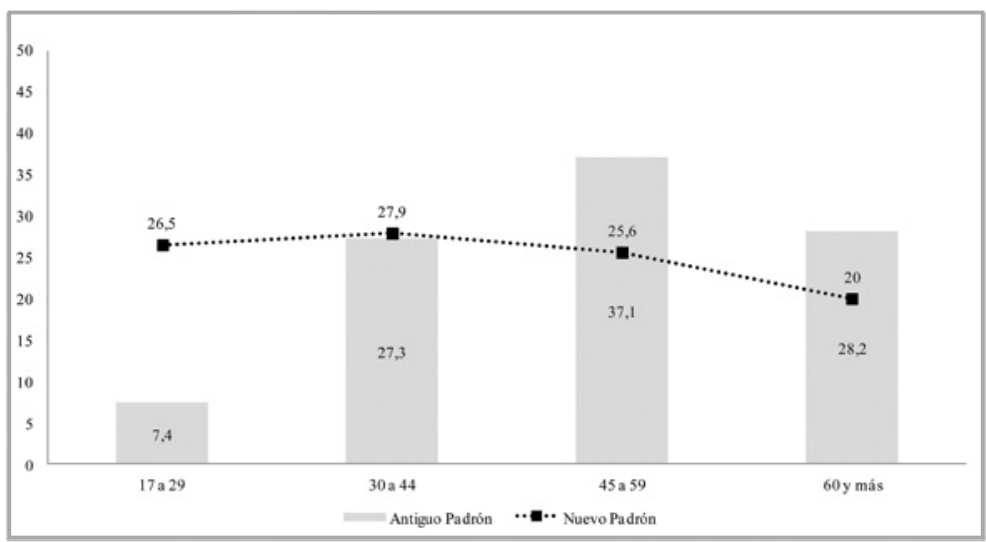

Fuente: Elaboración propia con datos de www.servel.cl

La baja participación y el escaso número de jóvenes inscritos en los registros electorales fueron las dos grandes razones que motivaron la reforma. Por un lado, 
se impulsó la inscripción automática en los registros electorales. Por otro, la voluntariedad del sufragio. El argumento fue que en el antiguo régimen de inscripción voluntaria, los potenciales nuevos votantes debían pagar el costo que implicaba inscribirse ante la junta electoral correspondiente. Si bien ese costo no era monetario, sí implicaba una inversión de tiempo que pocos estaban dispuestos a realizar ${ }^{22}$. Despejada esa discusión, cuyos argumentos fueron atendibles y consensuados por todos los partidos políticos, el debate giró en torno a la voluntariedad u obligatoriedad del voto. Las encuestas realizadas por la UDP en 2009 y 2010 mostraron que el voto voluntario era ampliamente preferido por la ciudadanía (más del 70\%). Probablemente, esto incidió en la decisión de respaldar la reforma.

¿Qué obvió el legislador al momento de planificar la reforma? Más allá de la popularidad del voto voluntario en la ciudadanía, el legislador no consideró el contexto institucional de la reforma. El voto voluntario coexistiría con un sistema electoral (el sistema binominal) que desestimulaba la competencia y que congelaba a la elite en dos grandes coaliciones ${ }^{23}$. De hecho, ambas coaliciones (Concertación y Alianza) suman casi el $90 \%$ de los votos (Ver gráfico 3). Teóricamente, basta con que una coalición obtenga un tercio de los votos para asegurarse un escaño en cualquier distrito. En consecuencia, es posible que con un tercio de los votos, una coalición obtenga la mitad de los escaños. Esto trae como efecto una baja competitividad. Para obtener los dos escaños en algún distrito una coalición requiere duplicar la votación de la coalición que llega en segundo lugar, lo que se torna difícil de conseguir. Visto así, los ciudadanos pueden predecir quiénes serán electos en sus distritos, sintiendo que su voto es escasamente relevante para influir en la elección.

La reforma al régimen electoral, entonces, convivía con un sistema electoral escasamente competitivo. Además, las experiencias de cambio desde un régimen obligatorio a otro voluntario (Holanda y Venezuela) señalaban contundentemente que se producía una caída en la participación ${ }^{24}$. En consecuencia, la democracia chilena podría convivir con baja participación (por el voto voluntario) y baja

\section{NAVIA, 2004.}

23. Chile tuvo hasta 2017 un sistema bicameral compuesto por 120 diputados y 38 senadores. En cada distrito o circunscripción se elegían 2 representantes. La fórmula de repartición de los escaños es d'Hondt. Generalmente, eran electos los candidatos más votados de las dos listas más votadas. Una lista podía llevarse los dos escaños siempre y cuando duplicara en votación a la lista que le seguía.

24. JaCKMAN, 1987; JaCKMAN y Miller, 1995. 
competencia (por el sistema electoral binominal)25. Es decir, estarían en peligro las dos dimensiones centrales de la poliarquía ${ }^{26}$. ¿Por qué, entonces, los legisladores apoyaron el voto voluntario?, ¿hubo algún cálculo estratégico previo a la reforma o solo primaron argumentos netamente normativos?, ¿qué explica el cambio de opinión de los legisladores de la Concertación que votaron a favor del voto voluntario pero que apoyaban el voto obligatorio?

\section{Gráfico 3.}

Porcentaje de votos de la Concertación y Alianza en las elecciones de diputados 1989-2009

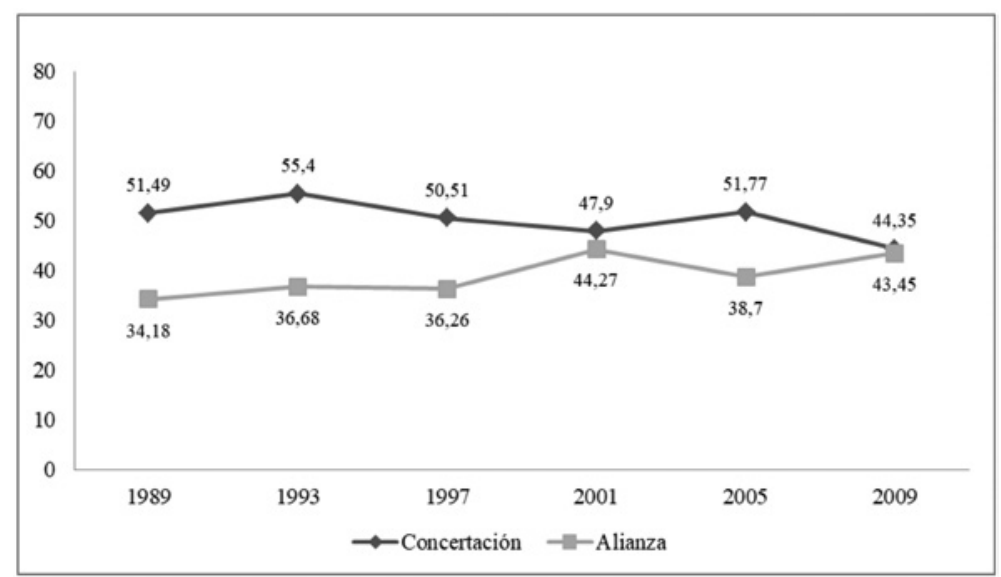

Fuente: Elaboración propia con datos de www.elecciones.gov.cl

\section{3. ¿Existían estudios de participación electoral que alertaran al legislador?}

Previo a la reforma se publicó abundante literatura sobre participación electoral en Chile ${ }^{27}$. Algunos estudios se concentraron en las variaciones de la votación nula y blanca $^{28}$, la abstención electoral ${ }^{29}$, y en el declive en la participación en los sectores

25. Morales, 2011.

26. DAHL, 1997.

27. Parker y Salvat, 1992; Parker, 2003; Navia, 2004; Fuentes y Villar, 2005; Huneeus, 2006; Carlin, 2006; Fontaine et al, 2007; Toro, 2008.

28. Carlin, 2006.

29. Parker, 2003; Cantillana, 2009. 
más pobres ${ }^{30}$. La preocupación central estuvo en explicar la significativa caída de la participación electoral identificando algunas causas. Entre ellas destaca el natural declive de la participación después del plebiscito sucesorio de 1988. En ese entonces, la lucha contra la dictadura impulsó a los ciudadanos a asistir masivamente a las $u_{r n a s}{ }^{31}$. Lo que estaba en juego era el tipo de régimen político para Chile. Los ciudadanos debían optar entre la democracia y la continuidad de la dictadura. De ahí en adelante y cuando la democracia no estaba en juego, la participación bajó. Poco a poco los ciudadanos dejaron de votar y, junto con ello, se instaló un malestar generalizado con los partidos. De hecho, las tasas de identificación partidaria también disminuyeron de manera significativa. Sin mediar una gran crisis económica ni una crisis política de gran magnitud, el distanciamiento de los ciudadanos con los partidos parecía irreversible.

Adicionalmente, y en comparación con las democracias andinas, Chile tampoco presenta serios problemas de estatalidad. Las falencias de los estados para proveer de bienes y servicios básicos a la comunidad explica muy sustantivamente la lejanía de los ciudadanos con la política ${ }^{32}$. En Chile no existe esa condición y de todos modos la participación ha caído a un ritmo preocupante. Una hipótesis alternativa viene desde la teoría de la modernización. En las democracias industrializadas avanzadas los ciudadanos se distancian de la política debido a que no ven en los partidos agencias relevantes para su progreso individual ${ }^{33}$. En su lugar, prefieren a los medios de comunicación como canales de información e incluso de representación. No es que exista un rechazo hacia los partidos o hacia la actividad política. Simplemente, los partidos pasan a ser instituciones poco relevantes. El esfuerzo individual es suficiente para mejorar las condiciones de vida y, desde esa perspectiva, los partidos son innecesarios.

Por tanto, el legislador sí contó con información relevante en torno a las características de la participación electoral y las razones de su caída. Un hecho objetivo era, precisamente, que la participación venía a la baja y que los jóvenes prácticamente no se inscribían en los registros electorales. Sobre esto último, los trabajos del Instituto de la Juventud (INJUV) a través de las Revista Observatorio de Juventud contribuyeron a entender dicha realidad. Igualmente, los trabajos de

30. Morales, 2011, Corvalán y Cox, 2011.

31. Navia, 2004; Toro, 2008; Contreras y Navia, 2013.

32. Mainwaring et al, 2006.

33. Dalton, 1999 y 2000; Dalton y Weldon, 2007. 
Parker ${ }^{34}$ analizaron el incremento de la abstención en los jóvenes. En este contexto, tomó fuerza la tesis del cambio generacional. Los trabajos de Madrid ${ }^{35}$ y Toro $^{36}$ fueron pioneros, avanzando en las causas de la baja participación juvenil y en las razones que esgrimían los jóvenes para distanciarse de la política. Corvalán y $\operatorname{Cox}^{37}$, por su parte, mostraron que el declive de la participación electoral se explicaba porque las nuevas generaciones (menores de 30 años) participan notablemente menos que las generaciones anteriores (mayores de 35 años). En el caso de los menores de 30 años, además, los autores demuestran la existencia de un pronunciado sesgo en el nivel socioeconómico de quienes participan. De acuerdo a la evidencia de los autores, la participación es significativamente más alta en los sectores ricos en comparación a los sectores pobres.

Con motivo de la discusión sobre el voto voluntario, la literatura fue más abundante aún, enfrentando el debate de manera directa. Fuentes y Villar ${ }^{38}$ apilaron una serie de argumentos a favor de ambas posturas. Asimismo, un trabajo compilatorio de algunos centros de estudio mostró algunos elementos normativos a considerar para la implementación de un nuevo sistema de votación ${ }^{39}$. Otros estudios mostraron los beneficios de disminuir las barreras de entrada propiciando la inscripción automática ${ }^{40}$. Para ello se basaron, entre otras cosas, en la evidencia comparada que avala los efectos positivos del registro automático ${ }^{41}$.

En consecuencia, tanto el Ejecutivo como el Legislativo contaron con suficientes antecedentes para tomar la decisión correcta. Por un lado, existían hechos objetivos como la baja participación, las barreras de entrada que implicaba la inscripción voluntaria, la baja identificación con partidos y el escaso interés en la política. Por otro, existía conciencia respecto a los efectos del sistema electoral binominal en la percepción de competencia por parte de los electores. Sobre el cambio de inscripción voluntaria a inscripción automática, prácticamente no hubo oposición.

34. PARKer, 2003.

35. MADRID, 2005.

36. Toro, 2008.

37. Corvalán y Cox, 2011.

38. FuENTES Y Villar, 2005.

39. FonTAINE et al, 2007.

40. Navia, 2004; Huneeus, 2006.

41. Mitchell y Wlezien, 1995; Highton, 1997. 


\section{Historia de la ley y opinión de los congresistas}

Luego del retorno a la democracia hubo múltiples proyectos para reformar el régimen electoral ${ }^{42}$. Estos intentos mostraron una conducta ambivalente de los parlamentarios de la Concertación. En 1996 los senadores del PDC enviaron un proyecto para instaurar la inscripción obligatoria manteniendo la obligatoriedad del sufragio ${ }^{43}$ (boletín 1848-07). Luego, a comienzos de 1997, un diputado del Partido Socialista (PS) y otro del PDC, en conjunto con un parlamentario del partido de derecha Renovación Nacional (RN), enviaron un proyecto con el mismo propósito ${ }^{44}$ (boletín 1965-06). Sin embargo, en 1998, ocho diputados del PDC dieron la primera señal contradictoria ${ }^{45}$. Presentaron un proyecto (Boletín 2196-06) que buscaba eliminar las sanciones asociadas al incumplimiento de la obligación de sufragar para los inscritos en el padrón electoral. Posteriormente, el gobierno de Ricardo Lagos envió un proyecto de ley para hacer la inscripción automática y despenalizar a quienes no sufragaran ${ }^{46}$. Finalmente, en 2004 el senador PS José Antonio Viera-Gallo (PS) participó activamente de la moción que modificó constitucionalmente el régimen electoral, impulsando la inscripción automática y el voto voluntario (Boletín 354407). Esto da cuenta del tránsito de la postura concertacionista desde el voto obligatorio al sufragio voluntario. Si los primeros proyectos de ley presentados buscaban consolidar la opción del voto obligatorio, los que siguieron buscaban abiertamente instaurar la voluntariedad del sufragio. La figura 1 sintetiza los principales hitos de la reforma en serie de tiempo.

42. Contreras y Morales, 2013.

43. Los autores del boletín 1848-07 fueron los senadores Mariano Ruiz-Esquide y Nicolás Díaz, ambos del PDC.

44. Los autores de esta moción fueron los diputados José Antonio Viera-Gallo (PS), Ignacio Walker (PDC) y Luis Ferrada (RN).

45. Los diputados democratacristianos autores de esta moción fueron Eliana Caraball, Aldo Cornejo, Sergio Elgueta, José Miguel Ortiz, Antonella Sciaraffia, Rodolfo Seguel, Patricio Walker e Ignacio Walker.

46. A través del Boletín 3586-06, enviado como mensaje presidencial ( $\mathrm{N}^{\circ} 101-351$ ). 


\section{Figura 1.}

Proyectos de ley para modificar el régimen electoral en Chile, enviados por parlamentarios de la Concertación

\begin{tabular}{c|c|c|c|c|}
$\begin{array}{c}\text { boletín 1848-07 } \\
\text { buscó la } \\
\text { inscripción } \\
\text { obligatoria }\end{array}$ & $\begin{array}{c}\text { boletín 1965-06 } \\
\text { buscó la } \\
\text { inscripción } \\
\text { obligatoria }\end{array}$ & $\begin{array}{c}\text { boletín 2196-06 } \\
\text { buscó } \\
\text { despenalizar la } \\
\text { obligación de } \\
\text { sufragar }\end{array}$ & $\begin{array}{c}\text { boletín 3586-06 } \\
\text { buscó establecer } \\
\text { la inscripción } \\
\text { automática y } \\
\text { despenalizar la } \\
\text { obligación de } \\
\text { sufragar }\end{array}$ & $\begin{array}{c}\text { boletín 3544-07 } \\
\text { instauró la } \\
\text { inscripción } \\
\text { automática } \\
\text { y el sufragio } \\
\text { voluntario }\end{array}$ \\
\hline $\begin{array}{c}\text { Postura a favor del régimen electoral } \\
\text { obligatorio }\end{array}$ & Postura a favor de la inscripción automática y voto \\
voluntario
\end{tabular}

Fuente: Elaboración propia con base en todos los proyectos de ley revisados.

Una vez aprobada la reforma constitucional de 2009 y en medio de la discusión sobre la Ley Orgánica Constitucional que consagraría el voto voluntario en Chile desarrollada en 2011, los representantes de la Concertación comenzaron a dar señales de arrepentimiento. Como mencionamos anteriormente, una amplia porción de chilenos prefería el voto voluntario antes que el voto obligatorio $(70,9 \%$ en 2010 según la encuesta de la UDP). Esto dio poco espacio a los representantes de la Concertación para dar señales más explícitas de arrepentimiento, toda vez que ya existía la reforma constitucional y un acuerdo político para aprobar la ley que echaría a andar el voto voluntario. De hecho, diputados del PDC, en conjunto con dos diputados UDI y una diputada del Partido Regionalista de los Independientes $(\mathrm{PRI})^{47}$, enviaron un proyecto de ley para revocar la reforma constitucional que instituyó el voto voluntario. A través del Boletín 8062-07, los parlamentarios buscaron restablecer el sufragio obligatorio, aunque con desafiliación voluntaria del padrón electoral. Este proyecto de ley fue interpretado como una forma de borrar con el codo lo que se escribió con la mano.

Adicionalmente, la Concertación ya contaba con algunos informes que, basados en encuestas de opinión, sostenían que con voto voluntario se agudizaría el sesgo

47. Los autores del Boletín 8062-07 fueron los diputados del PDC Jorge Burgos, Eduardo Cerda, Aldo Cornejo, Jorge Sabag, René Saffirio, Víctor Torres y Mario Venegas. Se suman a ellos los diputados de la UDI Gonzalo Arenas y Gustavo Hasbún, además de la diputada Alejandra Sepúlveda del PRI. 
de clase y aumentaría el poder del dinero en las campañas electorales (La Tercera, 10 de diciembre de 2011, página 2). Por tanto, cualquier argumento contrario al voto voluntario sería leído más como una defensa de los intereses particulares de la Concertación y no como una señal de fortalecimiento de la democracia.

El arrepentimiento de los representantes de la Concertación es constatable a partir de un estudio elaborado por el Observatorio Político-Electoral de la UDP que aplicó un cuestionario a los 120 diputados. Entre otras cosas, se preguntó por su preferencia hacia el voto obligatorio o voluntario. Solo uno de cada cuatro diputados de la Concertación apoyó el voto voluntario, mientras que en la Alianza ese apoyo fue de más de dos tercios. Esto marcaba una alta incongruencia programática entre los representantes de la Concertación y sus propios electores, que preferían ampliamente el voto voluntario.

¿Por qué es importante la referencia a la congruencia programática entre partidos y votantes? Teóricamente, Chile es clasificado como uno de los países con mayores niveles de congruencia programática entre partidos y electores en América Latina $^{48}$. Esta característica, si bien no necesariamente va asociada a un sistema de partidos institucionalizado, en el caso de Chile ambas condiciones parecen ir de la mano $^{49}$. Investigaciones más actualizadas discuten la real institucionalización del sistema de partidos en Chile ya sea por la pérdida de raigambre social de los par$\operatorname{tidos}^{50} \mathrm{o}$ por la incongruencia de partidos y electores al comparar representantes y votantes de las dos coaliciones más grandes ${ }^{51}$. Esto, fundamentalmente, porque si bien Chile muestra altos niveles de estabilidad en la votación hacia partidos en el contexto latinoamericano, tiene una de las tasas más bajas de identificación partidaria. Es decir, es un sistema de escasa volatilidad, pero también de baja raigambre social de los partidos.

Desde el análisis de la congruencia programática y de la preferencia por voto obligatorio o voluntario, los resultados indican que los diputados de derecha tienen un concepto relativo de libertad en materias políticas y valóricas. Son favorables al voto voluntario, pero contrarios a un cambio en el sistema electoral, a la distribución de la píldora del día después y a la despenalización del consumo de marihuana (Ver gráficos 4-7). Respecto al voto voluntario, dos tercios de la bancada

48. LunA y ZeChMeISTER, 2005 y 2010.

49. Mainwaring y Scully, 1995; Payne et al, 2003.

50. Morales, 2010; Luna y Altman, 2011.

51. Morales, 2011. 
de la Alianza lo apoyaban, mientras que en la Concertación solo alcanza el 25,9\%. Como muestra el gráfico 4, la congruencia entre representantes y votantes es mucho más significativa al considerar los diputados de la Alianza, pues los ciudadanos también apoyan mayoritariamente el voto voluntario incluso controlando según la coalición que prefiere cada uno. Los diputados de la Alianza, por otro lado, son conservadores a la hora de evaluar un cambio en el sistema electoral. Un tercio de la bancada está por mantener el binominal sin modificación alguna, cifra muy distante de lo que sucede tanto con la ciudadanía como con los diputados de la Concertación (Ver gráfico 2).

Lo anterior lleva a constatar dos cuestiones centrales. Los diputados de la Alianza son reformistas en materia de régimen electoral, pero conservadores en materia de sistema electoral. Una serie de autores ha constatado que el sistema binominal benefició a los partidos de derecha al inicio de la nueva democracia ${ }^{52}$. Al mismo tiempo, este sistema tiende a sobrerrepresentar a las segundas mayoría que, viendo distrito a distrito, frecuentemente son de la Alianza ${ }^{53}$. En consecuencia, los diputados de derecha no tienen ningún incentivo para impulsar una reforma al sistema electoral. En cambio, sí son favorables a ampliar el padrón. Seguramente, estimaron que la participación decaería, concentrándose solo en los votantes más ideologizados o polarizados. De hecho, y según la encuesta UDP de 2011, eran precisamente los encuestados de derecha los que mostraban una mayor predisposición a votar. Al mismo tiempo, y ante la inminencia de que el gasto en campañas aumentaría, eran los partidos de derecha los mejor dotados para enfrentar ese incremento del gasto. Finalmente, y dado el sesgo de clase que se agudizaría con el régimen de voto voluntario, los partidos de derecha saldrían beneficiados dado que, aparentemente, eran los más ricos quienes mostraban mayor predisposición a votar.

52. Rabkin, 1996; Rahat y Sznajder, 1998; Siavelis, 1997, 2004 y 2006; Cabezas y Navia, 2005.

53. Magar et al, 1998; Huneeus, 2006. 


\section{Gráfico 4.}

Apoyo al voto voluntario comparandociudadanos y diputados

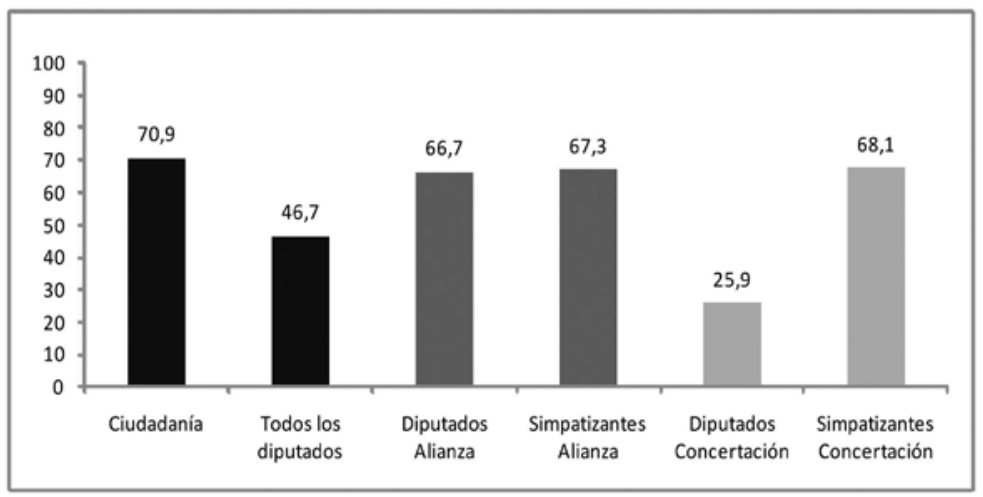

Gráfico 5.

Apoyo a mantener el sistema electoral binominal, comparando ciudadanos y diputados

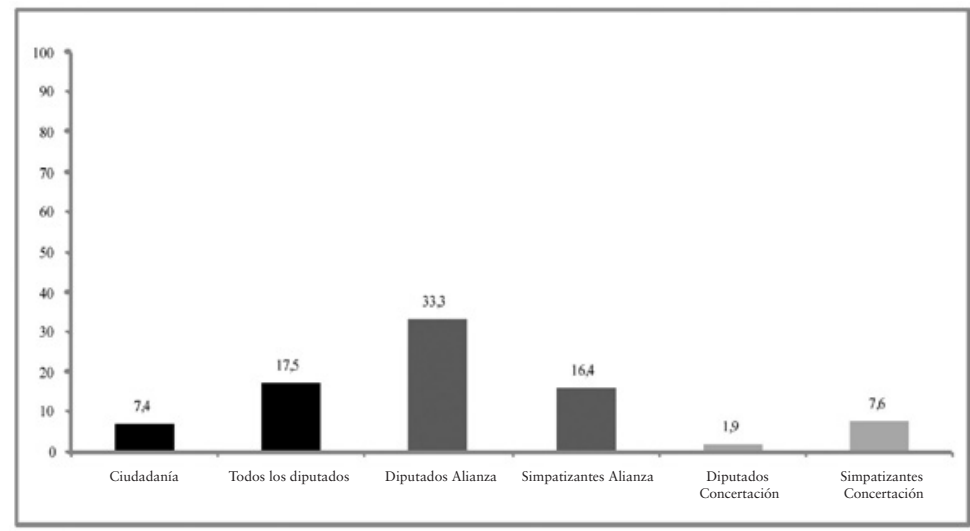

Gráfico 6.

Apoyo a la distribución gratuita de la píldora del día después para mujeres de escasos recursos, comparando ciudadanos y diputados

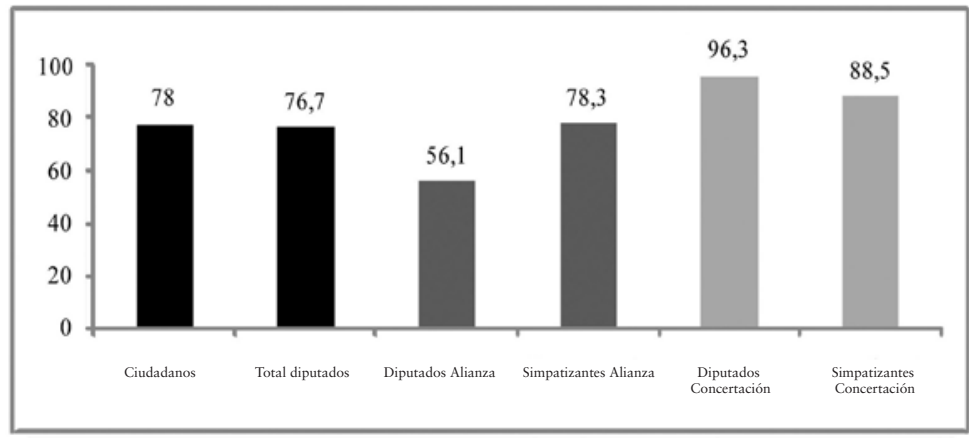




\section{Gráfico 7.}

Porcentaje de encuestados que están de acuerdo con despenalizar el consumo de marihuana, comparando ciudadanos y diputados

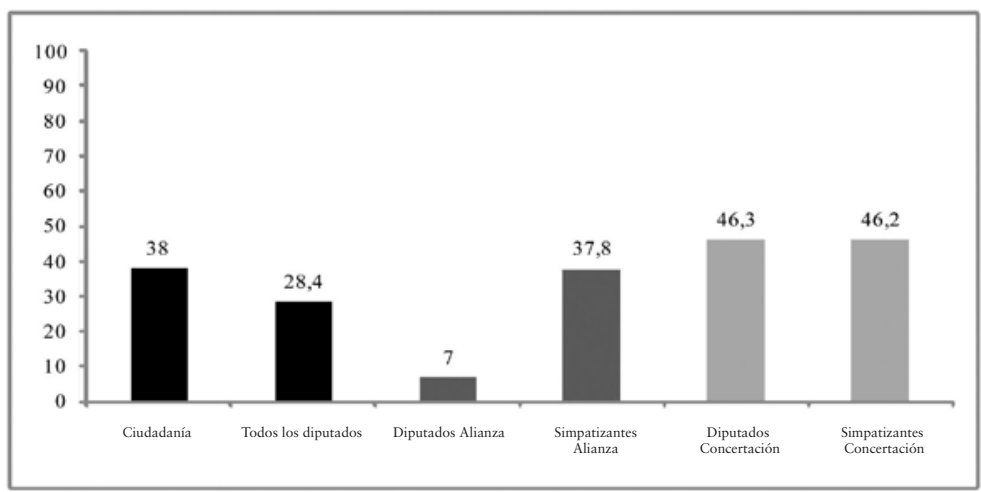

Fuente: Elaboración propia con datos de la encuesta a elite del Observatorio Político-Electoral y con datos de la encuesta UDP 2010.

\section{5. ¿Qué llevó a la Concertación a respaldar el voto voluntario?}

Si bien en la primera etapa de discusión sobre el voto voluntario primó el debate normativo a nivel público (lo que no es contradictorio con las cifras que se manejaban a nivel privado), creemos que la Concertación tuvo suficientes argumentos empíricos para apoyar el voto voluntario. Como muestra el gráfico 8, la población no inscrita de izquierda y de centro era mayoritaria en comparación a la de derecha. Por tanto, el incentivo de incorporar automáticamente a todos los no inscritos y a sabiendas de que estos no inscritos eran renuentes a votar, lo más razonable era incluirlos pero no obligarlos a ejercer el sufragio. El amplio apoyo hacia el voto voluntario particularmente en este grupo movió a la Concertación a inclinarse, precisamente, por la alternativa de la inscripción automática y del voto voluntario. $\mathrm{Al}$ analizar la composición de los no inscritos según escala política, observamos que casi los dos tercios son de centro-izquierda, dejando el 10\% para la derecha. El restante corresponde a no inscritos sin adscripción ideológica.

Sin embargo, hay un punto a discutir. Una cosa es el volumen de nuevos votantes de centro-izquierda, y otra muy distinta su real predisposición a votar. En la encuesta UDP de 2011, y considerando solo a no inscritos, el 23\% se identificaba con la izquierda, el 31\% con el centro y el 9,5\% con la derecha. Como muestra el gráfico 9 , los electores de centro tenían la menor predisposición a votar, lo que es respaldado por una simple prueba de proporciones. Es cierto que el centro era la 
opción preferida por los no inscritos y que a nivel absoluto su menor predisposición a participar no necesariamente implicaba un riesgo de pérdida de apoyo para el PDC, partido definido como de centro. El punto acá es que en la discusión política esta evidencia causó incertidumbre.

En la sesión del Consejo Nacional del PDC el 19 de noviembre de 2010, un alto dirigente señaló que "el voto voluntario no solo deprimirá la participación electoral, sino que además podría producir un daño a nuestro partido. La base electoral del PDC está en los ciudadanos de centro que hoy votan con voto obligatorio, pero lo dejarán de hacer si el voto es voluntario. Por eso, le pido a la directiva que tome cartas en el asunto". Otro miembro del Consejo sostuvo que "la discusión sobre si el voto es obligatorio o voluntario tiene que ver con el tipo de ciudadano que queremos para Chile, más allá de si nos vemos o no favorecidos. Para mí, el voto debe ser obligatorio por una cuestión de convicción”. Esta convivencia de argumentos empíricos y normativos no fue suficiente para que los diputados cambiaran de opinión, sin perjuicio de que algunos intentaran incluir a última hora algunos incentivos a la participación electoral.

\section{Gráfico 8.}

Inscritos y no inscritos según identificación ideológica

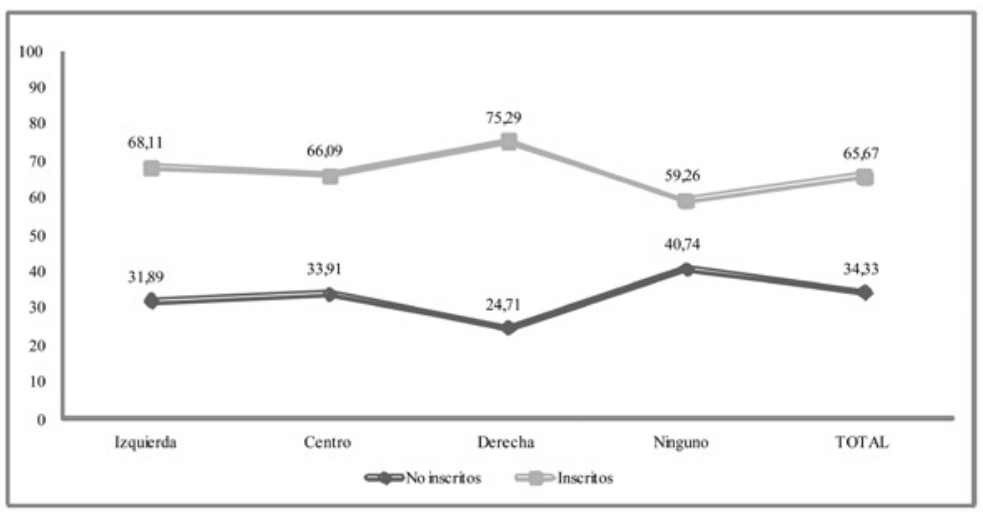

Fuente: Elaboración propia con datos de la encuesta UDP 2011 


\section{Gráfico 9.}

Porcentaje de encuestados que votaría con voto voluntario según identificación ideológica de inscritos y no inscritos

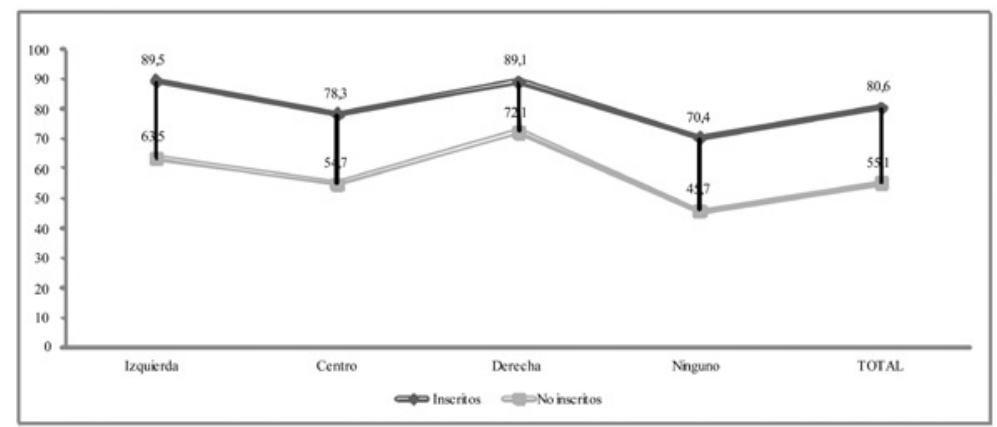

Fuente: Elaboración propia con datos de la encuesta UDP 2011

\section{Los efectos esperados del voto voluntario para gobierno y oposición}

Un ingreso de más de 5 millones de nuevos electores generó incertidumbre en los partidos políticos. Estaba claro que de los 13,4 millones de personas habilitadas para votar solo una fracción acudiría a las urnas, pero de todas formas eran potenciales votantes. Ante este panorama, surgió la pregunta respecto a las características de las comunas donde el ingreso de nuevos votantes sería más masivo. Se concluyó que las comunas con mayor incertidumbre (es decir, con más entrada de nuevos votantes) eran las de niveles medios de desarrollo humano. Estas comunas habían recibido parte importante de la migración campo-ciudad, y eran polos urbanos de amplio desarrollo. Nos referimos particularmente a comunas periféricas de Santiago como Puente Alto y Maipú, entre otras. Las comunas más ricas, en cambio, mostraban una menor entrada de nuevos votantes ya que ahí los ciudadanos tienden a inscribirse en mayor medida en los registros electorales que en las comunas urbanas más pobres.

Como señalamos, el incremento en el número de electores en comunas periféricas de Santiago y en algunas capitales regionales se explicó sustantivamente por los procesos migratorios y porque muchas personas no notificaban sus cambios de domicilio ante el Servicio Electoral. Esto hizo que la masa de nuevos votantes aumentara significativamente en las comunas receptoras de migrantes y que se deprimiera en las comunas de origen, lo que trajo como consecuencia que en las comunas de origen (preferentemente rurales) se mantuviera más o menos estable el 
número de ciudadanos en edad de votar. No es que necesariamente ahí la gente se inscribiera más que en otro tipo de comunas. Simplemente, sucedió que los nuevos electores (predominantemente jóvenes), buscaron mejores condiciones de vida en la ciudad sin cambiar su registro electoral.

El gráfico 10 corresponde a una simulación estadística que correlaciona el índice de desarrollo humano (IDH) por comuna con el porcentaje de crecimiento del padrón. Como se advierte, las comunas con mayor ingreso de nuevos votantes fueron las de ingreso medio. En tanto, las comunas ricas y las comunas pobres tuvieron menor entrada de nuevos votantes. ¿Qué implicancias político-electorales generó esta información? De acuerdo a elecciones previas, la base social más fuerte de la Concertación se encontraba, precisamente, en las comunas de IDH medio. Con el nuevo régimen electoral de voto voluntario, la incertidumbre en estas comunas sería mucho mayor. Esto explica, entonces, por qué algunos parlamentarios de la Concertación y especialmente del PDC intentaron frenar la aplicación del voto voluntario.

Una visión optimista para la Concertación indicó que en estas comunas los nuevos electores podrían comportarse de manera similar a los actuales votantes. Si se confiara en que los procesos de socialización funcionan y que existe una transmisión intergeneracional del voto, entonces la Concertación podría salir fortalecida en las comunas donde ya tenía bases electorales consolidadas. Una visión negativa, en tanto, indicó que la Concertación se veía amenazada justamente en los lugares donde tenía una significativa seguridad electoral dada su derrota en las presidenciales de 2010.

Otro temor de la Concertación, y especialmente en el PDC, fue -como señalamos- que la participación sería sustantivamente mayor en los segmentos de izquierda y de derecha en desmedro del centro. Para aclarar los supuestos que manejaba la Concertación y que explican el cambio de opinión de sus parlamentarios, construimos dos modelos probit con datos de la encuesta UDP de 2011. El objetivo es identificar los predictores de algunos grupos de votantes. La variable dependiente es si el encuestado está o no dispuesto a votar considerando que el voto es voluntario. Cruzamos esta variable con la pregunta de si la persona está o no inscrita en los registros electorales. Así, construimos cuatros grupos: inscritos (o antiguos votantes) que votan, inscritos que no votan, no inscritos que votan, no inscritos que no votan.

Las variables independientes, en tanto, son las siguientes:

a) Escala política. La encuesta incluye la pregunta sobre el autoposicionamiento de las personas en la escala 1 (muy de izquierda) a 10 (muy de derecha). 
Nuestra hipótesis es que con voto voluntario la fuga de electores es más fuerte en el centro de la distribución, lo que respaldaría nuestra idea de que la Concertación, y particularmente el PDC, quiso echar pie atrás en la reforma dada la fuga de electores moderados. Esto obedece a que los electores de centro muestran menores niveles de interés en la política y, por tanto, son los menos dispuestos a votar o a seguir votando.

b) Índice agregado de identificación. La encuesta incluye dos preguntas de identificación. La primera es la típica pregunta sobre identificación con partidos. La segunda es la pregunta de identificación con coaliciones. Dado que el sistema electoral binominal hace más visible las coaliciones que los partidos, es razonable construir un índice de identificación sumando ambos tipos de identificación. Nuestra hipótesis es que, naturalmente, los más identificados tienen mayor predisposición a votar que los menos identificados.

c) Nivel socioeconómico (GSE). Incluimos esta variable bajo la hipótesis de que con voto voluntario son los más ricos los que muestran mayor predisposición a votar en comparación a los más pobres, agudizando el sesgo de clase de la participación electoral. Dicho sesgo ya existía con el régimen electoral anterior (inscripción voluntaria y voto obligatorio), pero el problema es que con voto voluntario este sesgo se agudiza, no se corrige.

d) Edad. Nuestra hipótesis con esta variable es que tanto los fugados (inscritos que no votan) como los inscritos que quieren seguir votando son principalmente personas sobre 35 años. En tanto, los nuevos votantes (no inscritos que quieren votar) son predominantemente jóvenes.

e) Variables de control. El modelo queda sujeto a control con dos variables. Estas corresponden a zona de residencia ( $1=$ Región Metropolitana; $0=$ Resto del país) y sexo (1=Hombre; $2=$ Mujer).

Los gráficos 11 y 12 muestran los resultados de dos modelos estadísticos que predicen el grupo de inscritos o antiguos votantes que votan, e inscritos que no votan. Hemos excluido del análisis a los no inscritos que votan, pero de acuerdo a los resultados la única diferencia que tienen con el resto de los votantes es la edad. Claramente, los nuevos electores son más jóvenes, pero no tienen grandes diferencias políticas e ideológicas con el resto de la población.

La primera hipótesis tiene asidero empírico. Efectivamente, los votantes de centro son los que en mayor medida se fugan del antiguo padrón según esta encuesta de 2011 y que también se replicó para 2012. Esto traería como efecto una mayor polarización de las campañas políticas. Los partidos concentrarán sus esfuerzos en 
los votantes extremos. Es decir, en aquellos de mayor densidad ideológica y con mayores probabilidades de votar. Avanzar hacia votantes de centro podría ser una estrategia poco razonable dado lo costoso que sería generar adhesión y lograr que esos electores acudan a las urnas. En consecuencia, la percepción de derrota razonablemente fue más fuerte en el PDC cuya base electoral, como señalamos, está en los votantes moderados.

En segundo lugar, y asociado a lo anterior, la predisposición a votar según la encuesta es más alta en los ciudadanos con mayores niveles de identificación con partidos o coaliciones. Naturalmente, son votantes con preferencias políticas más cristalizadas. Como señalamos en el punto anterior, se autoubican en valores de izquierda o derecha de la escala, en desmedro de los valores de centro.

En tercer lugar, se advierte una profundización del sesgo de clase. Es cierto que con el régimen electoral previo a la reforma los ricos votaban más que los pobres. El problema es que con la instauración del voto voluntario esta situación se agudiza. Los electores inscritos que deciden seguir votando son predominantemente de sectores medios y altos.

Finalmente, está el efecto de la edad. Ciertamente, los nuevos electores son más jóvenes que el resto. En tanto, al comparar a los inscritos que siguen votando con los inscritos que dejan de votar, la edad tiene un efecto similar. Los inscritos que siguen votando tienen de 40-45 años hacia arriba, mientras que los inscritos que no votan son un tanto más jóvenes, pero en un rango similar.

En consecuencia, el nuevo régimen electoral traía las siguientes noticias:

a) Se producirían escasas variaciones en el volumen de participación (que se mantendría en torno al 60\%), pero sí cambiaría la composición de esta, siendo predominante el núcleo de votantes más ricos.

b) Se produciría una fuga significativa de votantes moderados, lo que afectaría especialmente al PDC.

c) Se produciría un incremento del gasto en campaña dado el mayor tamaño del padrón electoral, que pasó de 8 a más de 13 millones.

d) Todo esto traería como consecuencia claros beneficios para los partidos de derecha (los ricos votarían más que los pobres y el dinero sería más relevante en las campañas), mientras que el partido más perjudicado sería el PDC (dado la mayor fuga que generaría en el núcleo de votantes moderados). 
Gráfico 10.

Relación entre el IDH comunal y el porcentaje de crecimiento del padrón electoral (Modelo lineal)

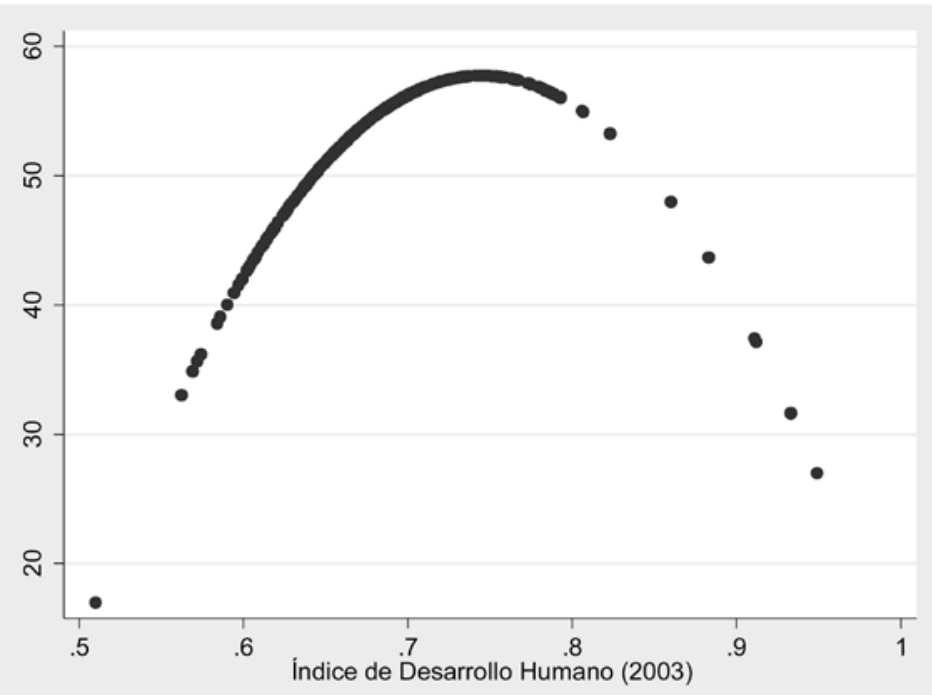

Fuente: Elaboración propia con datos de www.servel.cl y www.sinim.gov.cl

\section{Gráficos 11-12.}

Predictores de inscritos que votan y de inscritos que no votan (Modelos probit).

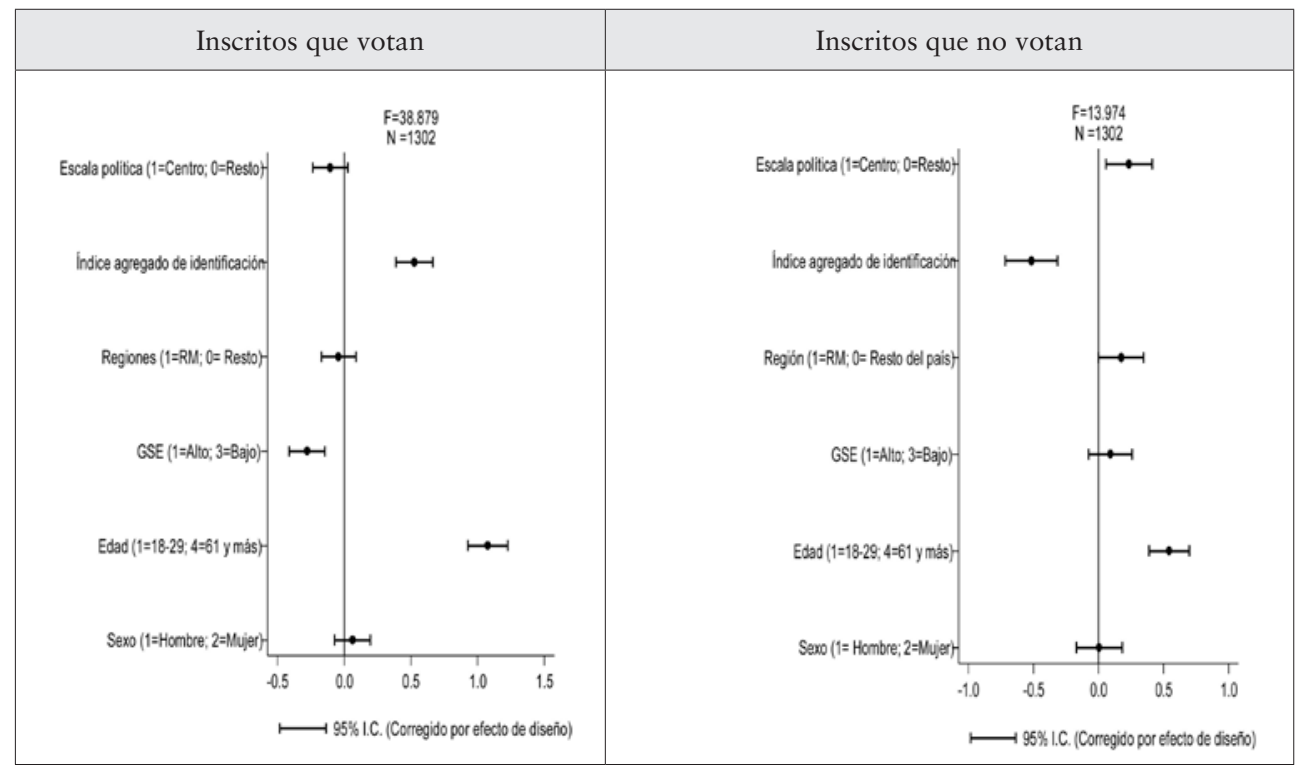

Fuente: Elaboración propia con datos de la encuesta UDP 2011. 
¿Y qué sucedió finalmente?, ¿se cumplieron los presagios pesimistas de la Concertación y especialmente del PDC? En la elección de concejales los resultados muestran más continuidad que cambio (Ver tabla 1). Si bien tanto la Concertación como la Coalición vieron reducida su cantidad de votos, en términos porcentuales la Concertación cayó en 2 puntos y la Coalición en 3. Para efectos comparativos, en la elección de 2012 excluimos al Partido Comunista (PC), que formó parte de uno de los pactos en que compitió la Concertación. En 2008, el PC compitió en el pacto Juntos Podemos Más.

Las mayores diferencias se dieron a nivel de alcaldes. La Concertación obtuvo 163 alcaldías (16 más que en 2008, sin incluir al PC que obtuvo 4). La Coalición, en cambio, totalizó 121 alcaldías, cifra significativamente inferior a las 144 que logró en 2008. Como en Chile el tamaño de las comunas es variable, construimos un indicador de población gobernada. No es lo mismo ganar una comuna de 500 habitantes que una comuna de más de 300 mil habitantes. Así, por ejemplo, si en 2008 la Concertación gobernaba al 36,7\%, en 2012 pasó a gobernar al 47,9\%. La Coalición, en tanto, gobernó al $47,8 \%$ de la población en 2008 , bajando a $37,2 \%$ en 2012 (ver gráfico 13). Por tanto, los cambios fueron sumamente significativos y a favor de la Concertación.

Así, el cálculo original de la Concertación (y particularmente del PDC) no tuvo asidero en la elección municipal. Contrario a su pesimismo estratégico (por el hecho de haber tratado a última hora de frenar la aplicación del voto voluntario), obtuvo un impensado buen resultado. Ahora bien. Su éxito no se explica necesariamente por el voto voluntario, pero sí resultó más o menos evidente que la Concertación tenía una base social más sólida y disciplinada que la Coalición. El pacto de gobierno perdió grandes comunas urbanas, y aunque su votación en concejales solo disminuyó en 3 puntos, la sensación de derrota fue más fuerte por la pérdida de comunas donde había gobernado por más de un período. Es justo señalar que la Coalición enfrentó estas elecciones municipales con un gobierno que apenas tenía un tercio de aprobación presidencial, lo que fue una importante desventaja.

Otra de las hipótesis en torno a los efectos del voto voluntario consistía en la reproducción del sesgo de clase. Es decir, que se votara más en las comunas ricas que en las comunas pobres. Para corroborar esto, construimos un modelo de regresión lineal donde la variable dependiente es el porcentaje de abstención en las municipales 2012 por comuna. Las variables independientes, en tanto, corresponden a la abstención en la municipal de 2008, el tamaño de la comuna medido a través de su padrón electoral, la presencia de un candidato a alcalde incumbente, 
el porcentaje de pobres, y la competencia, medida a través de la diferencia entre el porcentaje de votos del ganador y el que llegó segundo. Adicionalmente, incluimos un término de interacción entre pobreza y competencia. Esto último, porque creemos que la abstención no responde de manera autónoma al nivel socioeconómico de las comunas, sino que también a la percepción de los votantes respecto a cuán estrecha es la elección. Seguramente, la abstención será más baja en comunas competitivas que en comunas no competitivas. Para medir la competencia calculamos la diferencia entre el candidato a alcalde ganador y el candidato que llegó en segundo lugar. Ciertamente, es un indicador que presenta algunas debilidades. Pueden existir comunas donde la competencia no se anticipó como estrecha, pero que en los resultados sí lo fue. $\mathrm{O}$, al contrario, pueden existir comunas donde se anticipaba una alta competencia, pero que en los resultados se marcó una diferencia significativa entre el primer y segundo candidato. La mejor forma de resolver esto sería contar con encuestas preelectorales para todas las comunas del país (345 en total). No tenemos esa información, por lo que el mejor proxy es el indicador que acabamos de señalar.

Los resultados del modelo lo resumimos en la tabla 2, donde mostramos una simulación estadística. Lo que hacemos es pronosticar el porcentaje de abstención de acuerdo a las variaciones en el porcentaje de pobres y en el índice de competencia, dejando constante el resto de las variables. Seleccionamos solamente las comunas urbanas que están por sobre los 70 mil electores. La idea es comparar comunas de tamaño más o menos homogéneo. Los resultados indican que a idénticos niveles de competencia, la abstención es muy similar en comunas ricas y en comunas pobres. Las diferencias se advierten cuando la competencia es menor. En este escenario, sí se observa una distancia significativa entre comunas ricas y comunas pobres. Como era de esperarse, en las comunas ricas vota más gente que en las comunas pobres.

Por ejemplo, en una comuna con $1 \%$ de pobres y en una competencia estrecha (de $1 \%$ de diferencia entre el ganador y el segundo), la abstención bordea el $60 \%$, cifra similar a lo que alcanza una comuna con el $50 \%$ de pobres. Por tanto, cuando existe competencia estrecha, la abstención es muy similar en comunas ricas y en comunas pobres. En cambio, cuando prácticamente no existe competencia (que acá hemos arbitrariamente definido con una diferencia de $20 \%$ o más entre el primero y el segundo), las cifras se modifican. Así, en una comuna con $1 \%$ de pobres la abstención alcanza casi el $60 \%$, mientras que en una comuna con el $50 \%$ de pobres, la abstención supera el $70 \%$.

En síntesis, los presagios pesimistas de la Concertación no encontraron mayor 
asidero al menos en esta elección. Es cierto que se reprodujo el sesgo de clase, pero esto obedeció no solo a la condición socioeconómica de las comunas, sino que también a factores políticos como la competencia electoral. Además, la Concertación derrotó a la Coalición en comunas urbanas grandes, incluyendo la capital, Santiago.

Tabla 1.

Resultados de las elecciones de concejales 2008 y 2012

\begin{tabular}{|lccc|}
\hline Concertación & 2008 & 2012 & Diferencia \\
PDC & & & \\
PS & 15,43 & 15,06 & $-0,37$ \\
PPD & 12,41 & 12,26 & $-0,15$ \\
PRSD & 10,58 & 9,91 & $-0,67$ \\
Subtotal & 6,71 & 5,71 & -1 \\
& 45,13 & 42,94 & $-2,19$ \\
Alianza & & & \\
UDI & 2008 & 2012 & Diferencia \\
RN & 17,8 & 15,72 & $-2,08$ \\
Subtotal & 18,24 & 17,15 & $-1,09$ \\
\hline
\end{tabular}

Fuente: Elaboración propia con datos preliminares del Servel, www.servel.cl

Gráfico 13.

Población gobernada por coalición, municipales 1992-2012

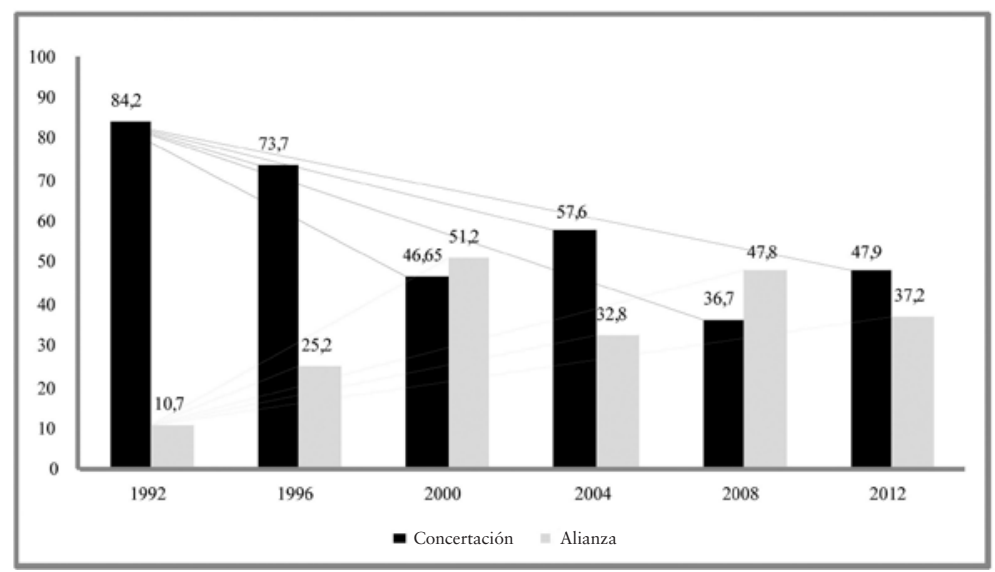

Fuente: Elaboración propia con datos preliminares del Servel, www.servel.cl 
Tabla 2.

Valores esperados de la abstención electoral, municipales 2012 (Modelo lineal)

\begin{tabular}{|c|c|c|}
\hline Porcentaje de pobres & Competencia (1\%) & Competencia $(20 \%)$ \\
\hline 1 & 59,7 & 59,9 \\
\hline 5 & 59,8 & 60,8 \\
\hline 10 & 59,8 & 61,8 \\
\hline 15 & 59,9 & 62,8 \\
\hline 20 & 59,9 & 63,9 \\
\hline 25 & 60,0 & 64,9 \\
\hline 30 & 60,1 & 65,9 \\
\hline 35 & 60,1 & 67,0 \\
\hline 40 & 60,1 & 68,0 \\
\hline 45 & 60,2 & 69,1 \\
\hline 50 & 60,3 & 70,1 \\
\hline 55 & 60,3 & 71,1 \\
\hline 60 & 60,4 & 72,2 \\
\hline 65 & 60,4 & 73,2 \\
\hline 70 & 60,5 & 74,3 \\
\hline 75 & 60,6 & 75,3 \\
\hline 80 & 60,7 & 76,4 \\
\hline
\end{tabular}

Fuente: Elaboración propia con datos de www.servel.cl y www.elecciones.gov.cl

\section{Conclusiones}

En 2009 se aprobó la reforma constitucional que instituyó el régimen de inscripción automática y voto voluntario y a principios de 2012 se promulgó la ley orgánicoconstitucional que regulaba su implementación. La elección municipal de 2012, donde debutó el nuevo régimen electoral, mostró la tasa de participación más baja luego del retorno a la democracia. Si en las elecciones municipales de 2008 la participación alcanzó el 58\% de participación, para 2012 solo votó el 41\% de las personas en edad de sufragar. 
En este artículo nos preguntamos por las motivaciones que tuvieron los legisladores para aprobar el régimen de inscripción automática y voto voluntario. A pesar de la abundante literatura y la conocida evidencia comparada sobre los efectos nocivos del voto voluntario, los parlamentarios discutieron, en una primera etapa, solo sobre la naturaleza normativa del voto, escondiendo los efectos empíricos que dicha decisión acarreaba. Todo esto, enmarcado en un ambiente de opinión pública claramente a favor del voto voluntario, y en un gobierno con altísimas tasas de popularidad. Los parlamentarios de la Concertación, dado este contexto, no tuvieron más que apoyar la reforma.

Luego de la aprobación de la reforma constitucional, los parlamentarios de la Concertación mostraron claras señales de arrepentimiento. Esto fue particularmente evidente luego de la derrota electoral de 2010. Una encuesta realizada por el Observatorio Político Electoral a los 120 diputados mostró que solo uno de cada cuatro se inclinaba por el voto voluntario, opinión muy diferente a la que tuvieron al momento de votar la ley orgánica. La brusca caída de la participación electoral ha llevado a algunos dirigentes de ambas coaliciones a proponer la restitución del voto obligatorio.

Así, la experiencia chilena muestra los vaivenes de una reforma al régimen electoral y los cambios en las opiniones de los legisladores. Lo que buscamos en este artículo fue explicar por qué se produjeron diferencias tan sustantivas entre la conducta legislativa y las opiniones de los diputados. Todo indica que el contexto de esta reforma, al ser consensuada en un gobierno muy popular, no abrió espacio para opiniones contrarias. Solo algunos académicos levantaron la voz, que fue escuchada después de la derrota electoral de la Concertación en 2010. Nuevamente, el contexto llevó a que parte importante de los diputados de la Concertación intentara echar pie atrás en una reforma que, en apariencia, tendría efectos negativos sobre sus propios intereses.

La opinión pública también ha mutado sus preferencias. La encuesta elaborada por el equipo que encabeza el "Proyecto Auditoría a la Democracia" (2012), que hizo su terreno inmediatamente después de las elecciones municipales, muestra que si en 2010 solo el $22 \%$ estaba a favor del voto obligatorio, en 2012 esta cifra se elevó al $41 \%$. El respaldo al voto voluntario, en tanto, decreció del 77\% al 57\% en estos mismos años. En consecuencia, nuevamente se observa una brecha entre elite y ciudadanía que ha reabierto la discusión en torno a las ventajas y desventajas del voto voluntario en Chile. 


\section{Referencias bibliográficas}

BENOIT, Kenneth (2004): “Models of electoral systems changes”. En Electoral Studies, Elsevier, vol. 23, No 3, pp. 363-389.

Bernhagen, Patrick y Marsh, Michael (2007): “The partisan effects of low turnout: Analyzing vote abstention as a missing data problem”. En Electoral Studies, Elsevier, vol. 26, $\mathrm{N}^{\circ}$ 3, pp. 548-560.

BlAIS, André (2008): “¿Qué afecta la participación electoral?”- En Revista Española de Ciencia Política, Asociación Española de Ciencia Política y de la Administración, vol. 18, $\mathrm{N}^{\circ}$ abril, pp. 9-27.

BoIx, Carles (1999): "Setting the rules of the game: The choice of electoral systems in advanced democracies". En American Political Science Review, Cambridge University Press, vol. 93, Nº 3, pp. 609-624.

Cabezas, José y Navia, Patricio (2005): "Efecto del sistema binominal en el número de candidatos y de partidos en elecciones legislativas en Chile, 1989-2001". En Política,INAP-Universidad de Chile, vol. 45, No primavera, pp. 29-52.

Cantillana, Carlos (2009): "Inscritos que no votan: la abstención electoral en Chile y sus factores explicativos". En Navia, Patricio, Morales, Mauricio y Briceño, Renato (eds.). El genoma electoral chileno. Dibujando el mapa genético de las preferencias politicas en Chile.(Santiago: Ediciones Universidad Diego Portales, pp. 76-96).

Carlin, Ryan (2006): "The Decline of Citizen Participation in Electoral Politics in Post-authoritarian Chile”, en Democratization, Taylor \& Francis, vol. 13, $\mathrm{N}^{\circ}$ 4, pp. 632-651.

Colomer, Josep (2007): “On the Origins of Electoral Systems and Political Parties”. En Electoral Studies, Elsevier, vol. 26, No 2, pp. 262-273.

Collier, David y Collier, Ruth (1991): Shaping the Political Arena: Critical Junctures, the Labor Movement, and Regime Dynamics in Latin America (Princeton, Princeton University Press).

Contreras, Gonzalo, González, Florencia, Morales, Mauricio y Oliva, Daniela (2012): "Nuevo régimen electoral en Chile. Inscripción automática y voto voluntario", en Morales, Mauricio y Navia, Patricio (eds.). Democracia Municipal en Chile, 1992-2010.(Santiago: Ediciones Universidad Diego Portales).

Contreras, Gonzalo y Navia, Patricio (2013): "Diferencias generacionales en la participación electoral en Chile, 1988-2010”. En Revista de Ciencia Política, PUC, vol. 33, N² 2, pp. 419-441.

Contreras, Gonzalo, Joignant, Alfredo y Morales, Mauricio (2015): “The Return 
of Censitary Suffrage? The effects of automatic voter registration and voluntary voting in Chile". En Democratization, Taylor \& Francis, vol. 23, $\mathrm{N}^{\circ} 3$, pp. 520-554.

Corvalán, Alejandro y Cox, Paulo (2011): “When generational replacement is class biased: Chilean turnout (1989-2008). En Latin American Politics and Society, University of Miami, vol. 55, No 3, pp. 47-68.

Cruz-CoKe, Ricardo (1984): Historia Electoral de Chile 1925-1973 (Santiago, Editorial Jurídica).

DAHL, Robert (1997): La poliarquia: participación y oposición (Madrid: Tecnos).

Dalton, Russell (1999): "Political Support in Advanced Industrial Democracies", en PIPA Norris (ed.). Critical Citizens. Global Support for Democratic Governance (Oxford, Oxford University Press).

DaLTon, Russell (2000): "Citizen attitudes and political behavior". En Comparative Political Studies, SAGE, vol. 33, No 6/7, pp. 912-940.

Dalton, Russell y Weldon, Steven (2007): "Partisanship and Party System Institutionalization". Party Politics, SAGE, vol. 13, No 2, pp. 179-196.

Fontaine, Arturo, Larroulet, Cristián, Viera-Gallo, José, Walker, Ignacio (2007): Modernización del régimen electoral chilen o(Santiago: CEP/CIEPLAN/ Libertad y Desarrollo/Proyectamérica).

Fuentes, Claudio y VILlar, Andrés (2005):Voto ciudadano. Debate sobre la inscripción electoral(Santiago: FLACSO-Chile).

Gallego, Aina (2010): “Understanding unequal turnout: education and voting in comparative perspective". En Electoral Studies,Elsevier, vol. 29, № 2, pp. 239-248.

GamboA, Ricardo. (2011): "Reformando las reglas electorales. La cédula única y los pactos electorales en Chile (1958 -1962)". En Revista de Ciencia Política, PUC, vol. 31, No 2, pp. 159-186.

Geys, Benny (2006): "Explaining voter turnout: A review of aggregate-level research". EnElectoral Studies, Elsevier, vol. 25, No 4, pp. 637-663.

Highton, Benjamin (1997): “Easy Registration and Voter Turnout”. En Journal of Politics, University of Chicago Press, vol. 59, No 2, pp. 565-576.

Huneeus, Carlos (2006): "La necesidad de la reforma electoral”. En Huneeus, Carlos (ed.).La reforma al sistema binominal en Chile: una contribución al debate (Santiago, Konrad Adenauer).

INDRIDASON, Indridi (2008): “Competition \& turnout: The majority run-off as a natural experiment”. En Electoral Studies, Elsevier, vol. 27, № 4, pp. 699-710.

JACKMAN, Robert (1987): "Political Institutions and Voter Turnout in the Industrial 
Democracies". En American Political Science Review, Cambridge University Press, vol. 81, No 2, pp. 405-423.

Jackman, Robert y MilLeR, Ross (1995): "Voter Turnout in the Industrial in the Industrial Democracies During the 1980s". En Comparative Political Studies, SAGE, vo. 27, $\mathrm{N}^{\circ}$ 4, pp. 467-492.

LehoucQ, Fabrice y Wall, David (2004): "Explaining voter turnout rates in new democracies: Guatemala”. En Electoral Studies, Elsevier, vol. 23, No 3, pp. 485-500.

LEVITSKy, Steven y RoberTs, Kenneth (2011): The Resurgence of the Latin American Left (Baltimore, The Johns Hopkins University Press).

LIJPHART, Arend (1997):“Unequal Participation: Democracy's Unresolved Dilemma. Presidential Address”. En American Political Science Review, Cambridge University Press, vol. 91, Nº1, pp. 1-14.

Luna, Juan y Zechmeister, Elizabeth (2010): "Political Representation in Latin America”. En Kitschelt, Herbet, Hawkins, Kirk, Luna, Juan, Rosas, Guillermo y ZeChMeIster, Elizabeth (eds.): Latin American Party Systems (Cambridge, Cambridge University Press, pp. 119-144).

Luna, Juan y Zechmeister, Elizabeth (2005): “The Quality of Representation in Latin America: A Study of Elite-Mass Congruence in Nine Countries". En Comparative Political Studies, SAGE, vol. 38, Nº 4, pp. 388-416.

Luna, Juan y Altman, David (2011): "Uprooted but Stable: Chilean Parties and the Concept of Party System Institutionalization". En Latin American Politics and Society, University of Miami, vol. 53, $\mathrm{N}^{\circ} 2$, pp. 1-28.

MADRID, Sebastián (2005): “¿Políticos de ayer, apáticos de hoy? Generaciones, juventud y política en Chile”. En Fuentes, Claudio y Villar, Andrés (eds.):Voto ciudadano. Debate sobre la inscripción electoral (Santiago: FLACSO-Chile, pp. 45-84).

Mackerras, Malcolm y McAllister, Ian (1999): "Compulsory voting, party stability and electoral advantage in Australia”. EnElectoral Studies, Elsevier, vol. $18, \mathrm{~N}^{\mathrm{o}} 2$, pp. 217-233.

Magar, Eric, Rosenblum, Mark y Samuels, David (1998): "On the Absence of Centripetal Incentives in Double-Member Districts". Comparative Political Studies, SAGE, vol. 31, N 6, pp. 714-739.

Mainwaring, Scott y Scully, Timothy (1995): "La institucionalización de los Sistemas de Partidos en América Latina". En Revista de Ciencia Política, PUC, vol. 17, $\mathrm{N}^{\circ} 1 / 2$, pp. 63-102.

Mainwaring, Scott, Bejarano, Ana y Pizarro, Eduardo (2006): The Crisis of Democratic Representation in the Andes. (Stanford, Stanford University Press). 
MAZA, Erika (1995): "Catolicismo, anticlericalismo y la extensión del sufragio a la mujer en Chile”. En Estudios Públicos, CEP, vol. 58, N Invierno, pp. 137-195.

Mitchell, Glenn y WLEzien, Christopher (1995): “The impact of legal constraints on voter registration, turnout, and the composition of the American electorate”. En Political Behavior, Springer, vol. 17, N² 2, pp. 179-202.

Morales, Mauricio (2010): “¿Quiénes son, dónde están, qué quieren?: las bases electorales de los candidatos presidenciales 2009”. En Reporte de Encuesta Nacional UDP 2009. Chile 2009: actitudes y percepciones sociales (Santiago, Ediciones UDP).

Morales, Mauricio (2011): "Precauciones frente al voto voluntario". EnICSO-UDP (ed.). Chile 2010. Sexta Encuesta Nacional UDP. Percepciones y actitudes sociales.(Santiago: Ediciones UDP).

Morales, Mauricio (2012): “Identificación partidaria en América Latina”. En Revista de Ciencias Sociales, Universidad del Zulia, vol. 17, No 4, pp. 583-597.

Morales, Mauricio (2012a): “The Concertación's Defeat in the 2009/2010 Presidential Elections in Chile".En Latin American Politics and Society, University of Miami, vol. 54, $\mathrm{N}^{\circ}$ 2, pp. 79-107.

Navia, Patricio (2004): “Participación electoral en Chile 1988-2001". En Revista de Ciencia Política, vol. 24, $\mathrm{N}^{\circ}$ 1, pp. 81-103.

NAviA, Patricio (2005): "La transformación de votos en escaños: leyes electorales en Chile, 1833-2004”.En Política y Gobierno, CIDE, vol. 12, No 2, pp. 233-276.

PARKer, Cristián (2003): "Abstencionismo, juventud y política en Chile actual”. Revista de Estudios Avanzados Inter@ctivos, USACH, vol. 2, No 4, pp. 1-23.

Parker, Cristián y SALVAT, Pablo (1992): Formación cívico-política de la juventud, desafío de la democracia. (Santiago, CERC-UAHV).

Payne, Mark, Zovatto, Daniel, Carrillo, Fernando y Allamand, Andrés (2003): La política importa. Democracia y desarrollo en América Latina (Washington, D.C., BID e Instituto Internacional para la Democracia y la Asistencia Electoral).

Rabkin, Rhoda (1996): "Redemocratization, Electoral Engineering, and Party Strategies in Chile, 1989-1995”. En Comparative Political Studies, SAGE, vol. 29, $\mathrm{N}^{\circ}$ 3, pp. 335-356.

Rahat, Gideon y Sznajder, Mario (1998): “Electoral Engineering in Chile: The Electoral System and Limited Democracy”. En Electoral Studies, Elsevier, vol. 17, No 4, pp. 429-442.

Rallings, Colin, Thrasher, Michael, Borisyuk, Galina (2003): “Seasonal Factors, 
Voter Fatigue and the Costs of Voting”. Electoral Studies, Elsevier, vol. 22, $\mathrm{N}^{\circ}$ 1, pp. 65-79.

Siavelis, Peter (1997): “Continuity and Change in the Chilean Party System”. En Comparative Political Studies, SAGE, vol. 30, No 6, pp. 651-674.

Siavelis, Peter (2004): "Sistema electoral, desintegración de coaliciones y democracia en Chile: ¿El fin de la Concertación?”. En Revista de Ciencia Política, PUC, vol. 24, $\mathrm{N}^{\circ} 1$, pp. 58-80.

Siavelis, Peter (2006): "Los peligros de la ingeniería electoral (y de predecir sus efectos)". En Politica, INAP-Universidad de Chile, vol. 45, No Primavera, pp. 9-28.

Toro, Sergio (2008): "De lo épico a lo cotidiano: Jóvenes y generaciones políticas en Chile”. En Revista de Ciencia Política, PUC, vol. 28, N 3, pp. 143-160.

Valenzuela, Arturo (2003): El quiebre de la democracia en Chile (Santiago, Ediciones UDP).

Wills-Otero, Laura (2009): "Electoral Systems in Latin America: Explaining the Adoption of Proportional Representation Systems During the Twentieth Century". En Latin American Politics and Society, vol. 51, No 3, pp. 33-58. 